\title{
Correlation of Clinical Features With the Mutational Status of GM-CSF Signaling Pathway-Related Genes in Juvenile Myelomonocytic Leukemia
}

NAO YOSHIDA, HIROSHI YAGASAKI, YINYAN XU, KAZUYUKI MATSUDA, AYAMI YOSHIMI, YOSHIYUKI TAKAHASHI, ASAHITO HAMA, NOBUHIRO NISHIO, HIDEKI MURAMATSU, NOBUHIRO WATANABE, KIMIKAZU MATSUMOTO, KOJI KATO, JUNICHI UEYAMA, HIROKO INADA, HIROAKI GOTO, MIHARU YABE, KAZUKO KUDO, JUNICHI MIMAYA, AKIRA KIKUCHI, ATSUSHI MANABE, KENICHI KOIKE, AND SEIJI KOJIMA

Department of Pediatrics [N.Y., H.Y., Y.X., Y.T., A.H., N.N., H.M., S.K.], Nagoya University Graduate School of Medicine, Nagoya 466-8550, Japan; Departments of Laboratory Medicine [K.M.], and Pediatrics [K.K.], Shinshu University Hospital, Matsumoto 390-8621, Japan; Department of HSCT Data Management [A.Y.], Nagoya University School of Medicine, Nagoya 461-0047, Japan; Department of Hematology and Oncology [N.W., K.M., K.K.], Japanese Red Cross Nagoya First Hospital, Nagoya 453-8551, Japan; Department of

Multidisciplinary Internal Medicine [J.U.], Tottori University, Yonago 683-8503, Japan; Department of Pediatrics [H.I.], Kurume University School of Medicine, Kurume 830-0011, Japan; Department of Pediatrics [H.G.], Yokohama City University Hospital, Yokohama 236-0044, Japan; Department of Cell Transplantation [M.Y.], Tokai University School of Medicine, Isehara 259-1193, Japan; Department of Pediatrics [K.K.], University of Tsukuba, Tsukuba 305-8575, Japan; Department of Hematology and Oncology [J.M.], Shizuoka Children's Hospital, Shizuoka 420-8660, Japan; Division of Hematology/Oncology [A.K.], Saitama Children's Medical Center, Saitama 339-8551, Japan; and Department of Pediatrics [A.M.], St. Luke's International Hospital, Tokyo 104-8560, Japan

\begin{abstract}
Mutations in RAS, neurofibromatosis type 1 (NF1), and PTPN11, constituents of the granulocyte-macrophage colonystimulating factor signaling pathway, have been recognized in patients with juvenile myelomonocytic leukemia (JMML). We assessed 71 children with JMML for NRAS, KRAS, and PTPN11 mutations and evaluated their clinical significance. Of the 71 patients, three had been clinically diagnosed with neurofibromatosis type 1, and PTPN11 and NRAS/KRAS mutations were found in 32 (45\%) and 13 $(18 \%)$ patients, respectively. No simultaneous aberrations were found. Compared with patients with $R A S$ mutation or without any aberrations, patients with PTPN11 mutation were significantly older at diagnosis and had higher fetal Hb levels, both of which have been recognized as poor prognostic factors. As was expected, overall survival was lower for patients with the PTPN11 mutation than for those without (25 versus 64\%; $p=0.0029$ ). In an analysis of 48 patients who received hematopoietic stem cell transplantation, PTPN11 mutations were also associated with poor prognosis for survival. Mutation in PTPN11 was the only unfavorable factor for relapse after hematopoietic stem cell transplantation $(p=0.001)$. All patients who died after relapse had PTPN11 mutation. These results suggest that JMML with PTPN11 mutation might be a distinct subgroup with specific clinical characteristics and poor outcome.
\end{abstract}

(Pediatr Res 65: 334-340, 2009)

$\mathrm{J}^{\mathrm{a}}$ uvenile myelomonocytic leukemia (JMML) is a rare clonal myelodysplastic/myeloproliferative disorder that affects young children. It is characterized by specific hypersensitivity of JMML cells to granulocyte-macrophage colony-stimulating factor (GM-CSF) in vitro, but is thought to be a genetically and phenotypically heterogeneous disease (1-4). JMML seems to have its genesis in dysregulation of GM-CSF signal

Received July 7, 2008; accepted October 6, 2008.

Correspondence: Seiji Kojima, M.D., Ph.D., Department of Pediatrics, Nagoya University Graduate School of Medicine, 65 Tsurumai-cho, Showa-ku, Nagoya 466-8550, Japan; e-mail: kojimas@med.nagoya-u.ac.jp. transduction, and gene mutations interfering with downstream components of the GM-CSF signaling pathway can be identified in approximately $70 \%$ of children with this disorder (2,5-11). Constitutional mutations of NF1 occur in approximately $10 \%$ of patients with JMML $(2,5,12)$. NFI is known to be the causative gene of neurofibromatosis type 1 (NF1), an autosomal dominant cancer predisposition syndrome. NFI codes for neurofibromin, a GTPase activating protein for Ras, and acts as a tumor suppressor (13). Similarly, oncogenic $R A S$ mutations at codons 12,13 , and 61 have been identified in approximately $20-25 \%$ of patients with JMML $(2,6-8)$. These mutations lead to elevated levels of Ras-GTP, the active form of Ras, resulting in constitutive activation of the signal transduction pathway (14).

Somatic mutations in PTPN11, which encodes the protein tyrosine phosphatase SHP-2, a molecule that also relays the signal from the GM-CSF receptor to Ras, have been reported in approximately $35 \%$ of patients with JMML $(9-11)$. Germline mutations in PTPN11 were first observed in Noonan syndrome (NS) (15), and somatic mutations have also been identified in hematological malignancies $(9-11,16,17)$. SHP-2 is a positive regulator in this signal transduction pathway and PTPN11 mutations cause gain of function in SHP-2, resulting in inappropriate activation of the GM-CSF pathway (10). PTPN11 mutations have been found without coexisting NRAS, KRAS, or NF1 mutations $(9,11,16)$. These alterations are thought to be responsible for GM-CSF hypersensitivity and the clinical features associated with this condition. Given this information, mutational analysis of PTPNII and RAS, or

Abbreviations: GM-CSF, granulocyte-macrophage colony-stimulating factor; HbF, fetal hemoglobin; HSCT, hematopoietic stem cell transplantation; JMML, juvenile myelomonocytic leukemia; NF1, neurofibromatosis type 1; NS, Noonan syndrome; OS, Overall survival 
either identification of an NF1 mutation or a clinical diagnosis of NF1, are currently key diagnostic procedures for JMML. However, we have a poor understanding of the relationship between mutational status and the clinical features of JMML.

Most patients with JMML usually experience an aggressive clinical course and die from progressive disease unless treated with hematopoietic stem cell transplantation (HSCT) $(1,4,18,19)$. Recent studies have shown that children with JMML have better outcomes when they undergo HSCT early in the course of the disease $(20,21)$. In contrast, there is a certain proportion of patients who have a stable clinical course for a considerable period of time, and disease that sometimes spontaneously resolves without any treatment $(1,22,23)$. Therefore, information on prognostic factors that can be used to identify patients requiring early HSCT is important in developing a treatment plan.

Although several clinical characteristics have been reported as prognostic factors for JMML, including age at diagnosis, sex, fetal $\mathrm{Hb}(\mathrm{HbF})$ level, platelet count, and cytogenetic abnormality (1,19-21,23-26), the relationship between prognosis and particular genetic aberrations is unclear and needs to be clarified. Thus, in the current study, we assessed 71 children with JMML for NRAS, KRAS, and PTPN11 mutations and analyzed the association between mutational status and previously recognized prognostic factors for JMML, then evaluated the clinical significance of these mutations to clarify whether genotype-phenotype correlations exist.

\section{MATERIALS AND METHODS}

Patients. A total of 71 children with JMML diagnosed between 1987 and 2006 in 30 institutions throughout Japan were studied retrospectively. The diagnosis of JMML was based on the internationally accepted criteria previously published (27). We excluded patients with NS, a JMML-like myeloproliferative disease characterized by spontaneous regression of the disease. The clinical and hematological characteristics of the 71 patients are summarized in Table 1. The median age at diagnosis was 24 mo (range, 1-69 mo).

Table 1. Patients characteristics

\begin{tabular}{lc}
\hline No. of patients & 71 \\
Median age at diagnosis, mo (range) & $24(1-69)$ \\
$\quad$ Male/female & $43 / 28$ \\
Peripheral blood & \\
$\quad$ Median Hb at diagnosis, g/dL (range) & $9.3(4.9-13.0)$ \\
Percentage of HbF at diagnosis (range) & $19.0(1.0-78.0)$ \\
Median WBC count at diagnosis, $\times 10^{9} / \mathrm{L}$ (range) & $31.8(7.6-563.0)$ \\
$\quad$ Median monocyte count at diagnosis, $\times 10^{9} / \mathrm{L}$ (range) & $4.2(1.0-84.5)$ \\
$\quad$ Median platelets count at diagnosis, $\times 10^{9} / \mathrm{L}$ (range) & $42.0(1.4-320.0)$ \\
Hepatomegaly (yes/no) & $67 / 4$ \\
Splenomegaly (yes/no) & $68 / 3$ \\
Cytogenetic study, no.of patients & \\
Normal & 55 \\
Monosomy 7 & 9 \\
Other abnormalities & 2 \\
$\quad+8$ & 1 \\
$\quad-$ Y & 1 \\
$\quad+X,+13$ & 1 \\
Inv(4)(p14p16) & 1 \\
$t(3 ; 18)(\mathrm{q} 25 ;$ q21) & 1 \\
$\quad$ Del(6)(q?), -20 & \\
No. of patients with clinical evidence of NF1 & 3 \\
No. of patients received HSCT & 48 \\
\hline
\end{tabular}

WBC, white blood cell.
Karyotypic abnormalities were detected in 16 patients, including nine patients with monosomy 7. Three children had clinical evidence of NF1. Treatment was planned in the institute responsible for each child and 48 of 71 patients had been treated with HSCT. The source of grafts was bone marrow from a related donor for 15 patients, bone marrow from an unrelated donor for 20 , unrelated cord blood for 11, and related peripheral blood for two. Total body irradiation, TBI, was used in half of the patients and the remainder underwent a non-TBI regimen in which the drug dosage varied widely. Approval for this study was obtained from the Ethics Committee of Nagoya University Graduate School of Medicine.

Screening for mutations of the PTPN11, NRAS, and KRAS genes. Written informed consent was obtained from the parents of each patient, and bone marrow or peripheral blood samples were obtained at initial diagnosis. Mononuclear cells were isolated using Ficoll-Hypaque density gradient centrifugation and they were cryopreserved until use. Genomic DNA was extracted using the QIAamp DNA Blood Mini Kit (Qiagen, Chatsworth, CA). To screen for PTPN11 mutations, we amplified genomic DNA corresponding to exons $2,3,4,7,8,12$, and 13 of PTPN11 using the PCR with cycling parameters and primers as previously reported $(28,29)$. The PCR products were purified and directly sequenced on an ABI Prism 3100 DNA Analyzer (Applied Biosystems, Foster City, CA) using a BigDye terminator cycle sequencing kit (Applied Biosystems).

NRAS and KRAS mutations of codons 12, 13, and 61 were identified as previously described $(11,30)$ and were confirmed by sequencing.

Analysis of correlations between clinical characteristics and mutational status. To assess the correlations between clinical characteristics and mutational status, patients were subdivided into four groups: those with a PTPN11 mutation, a RAS mutation, a clinical diagnosis of NF1, or none of these. However, the number of patients with NF1 was too small to allow subgroup analysis, so these patients were excluded from this analysis. Then, for the three remaining groups, we performed a comparison of clinical and laboratory findings.

Statistical analysis. The date of analysis was January 30, 2008. Survival probabilities were estimated by the Kaplan-Meier method and comparisons between probabilities for different patient groups were performed using the two-sided log-rank test. All results are expressed as 5-y probabilities with a 95\% confidence interval (CI). Overall survival (OS) for all patients was defined as the time from diagnosis to death or last follow-up. OS in patients who received HSCT was defined as the time from transplantation to death or last follow-up. Relapse incidence was defined as the probability of experiencing a relapse and death without relapse was considered a competing event. The parameters for univariate analyses of OS and relapse incidence included age at diagnosis, sex, platelet count, percentage of $\mathrm{HbF}$, karyotype, and mutational status. For multivariate analyses, the Cox proportional hazard regression model was used. To evaluate correlations between clinical characteristics and mutational status, differences in continuous variables were analyzed using the Mann-Whitney $\mathrm{U}$ test and differences in frequencies were tested using the $\chi^{2}$ test. When appropriate (because of small sample size), Fisher's exact test was used. p values less than 0.05 were considered statistically significant. These statistical analyses were performed with StatView-J 5.0 software (Abacus Concepts Inc., Berkeley, CA).

\section{RESULTS}

Mutation analysis. The results of the PTPN11 and NRAS/ KRAS mutational screening for the 71 Japanese children with JMML are listed in Table 2. We found PTPN11 mutations in 32 of $71(45 \%)$ patients. All mutations were missense changes, 30 of which were in exon 3 and two of which were in exon 13. Thirteen of 71 (18\%) patients had RAS mutations, 11 of which were in NRAS and two of which were in KRAS. Ten of 13 patients with $R A S$ mutations had been reported in a previous study (22). Three (4\%) patients were clinically diagnosed with NF1. No patient with NF1 was found to have mutations in PTPN11 or RAS, and 23 (32\%) patients had neither a $P T P N 11$ mutation nor a $R A S$ mutation, nor a clinical diagnosis of NF1.

Comparison of clinical characteristics of patients according to mutational status. We compared the laboratory and clinical parameters for patients with a PTPN11 mutation, with a $R A S$ mutation, and without any aberration (Table 3). In the 
group corresponding to individuals with a PTPN11 mutation, quite distinct characteristic features were evident, whereas there was no difference in the clinical characteristics displayed by individuals in the groups with a $R A S$ mutation and no aberration. Patients with PTPN11 mutations were significantly older at diagnosis (median: $35 \mathrm{mo}$ ) than those with $R A S$ mutations (median: $10 \mathrm{mo} ; p<0.0001$ ) or those without any aberrations (median: $10 \mathrm{mo} ; p=0.0037$ ), and the presence of the PTPN11 mutation in infants was rare (only two of 32 patients). In addition, the HbF level was significantly higher in the PTPN11 mutation group than in the RAS mutation group or the group with no aberration (25.6 versus $8.6 \% ; p=0.0026$ or versus $9.8 \% ; p=0.0014)$. The patients with monosomy 7 are known to have normal or only slightly elevated $\mathrm{HbF}$ levels

Table 2. PTPN11, NRAS, and KRAS mutations in 71 children with $J M M L$

\begin{tabular}{ccll}
\hline Gene & $\begin{array}{c}\text { No. of } \\
\text { patients }\end{array}$ & $\begin{array}{l}\text { Nucleotide } \\
\text { substitution }\end{array}$ & $\begin{array}{l}\text { Amino acid } \\
\text { substitution }\end{array}$ \\
\hline PTPN11 & 2 & $179 \mathrm{G}>\mathrm{T}$ & Gly60Val \\
4 & $181 \mathrm{G}>\mathrm{T}$ & Asp61Tyr \\
3 & $182 \mathrm{~A}>\mathrm{T}$ & Asp61Val \\
1 & $214 \mathrm{G}>\mathrm{A}$ & Ala72Thr \\
5 & $215 \mathrm{C}>\mathrm{T}$ & Ala72Val \\
11 & $226 \mathrm{G}>\mathrm{A}$ & Glu76Lys \\
1 & $226 \mathrm{G}>\mathrm{C}$ & Glu76Gln \\
3 & $227 \mathrm{~A}>\mathrm{G}$ & Glu76Gly \\
2 & $1508 \mathrm{G}>\mathrm{C}$ & Gly503Ala \\
\multirow{2}{*}{ NRAS } & $34 \mathrm{G}>\mathrm{A}$ & Gly12Ser \\
& 3 & $34 \mathrm{G}>\mathrm{T}$ & Gly12Cys \\
& 3 & $35 \mathrm{G}>\mathrm{A}$ & Gly12Asp \\
& 1 & $38 \mathrm{G}>\mathrm{A}$ & Gly13Asp \\
3 & $181 \mathrm{C}>\mathrm{A}$ & Gln61Lys \\
& 1 & Gln61Leu & Gly12Asp \\
& 1 & $35 \mathrm{G}>\mathrm{A}$ & Gly12Val \\
\hline
\end{tabular}

(1). When the patients with monosomy 7 were excluded from the analysis, strong correlations of higher $\mathrm{HbF}$ level with PTPN11 mutation compared with RAS mutation or no aberration were still observed $(p=0.0004$ or $p=0.0014$, respectively). Even after the groups other than the PTPN11 group were combined (including the patients with NF1), the factors of older age at diagnosis and higher $\mathrm{HbF}$ level were still significantly different between the PTPN11 mutation group and the other group. Karyotypic aberrations other than monosomy 7 occurred only in patients with the PTPN11 mutation. Patients with a PTPN11 mutation were more likely to receive HSCT than those with a RAS mutation or without any aberrations. As shown in Table 3, no correlation was observed between mutational subgroup and sex ratio, white blood cell count, or platelet count.

Because of the small number of patients in the NF1 group, we excluded these three patients from subgroup analysis. However, consistent with previous findings (1), children with NF1 had been given a diagnosis at an older age except for one patient with a family history (JMML was diagnosed in two girls with NF1 at 7 and 47 mo and in one boy with NF1 at $69 \mathrm{mo}$ ) but no other clinical parameters differed from those of the other mutational subgroups.

Prognostic impact of the GM-CSF signaling pathwayrelated genes. For all 71 children, the OS probability at $5 \mathrm{y}$ was $43 \%$ (95\% CI: 35-51), and the median follow-up time for all living patients was 59 mo (range, 13-240 mo). Given the quite distinct clinical characteristics of the PTPN11 mutation group, which associated with recognized poor prognostic factors, we compared the clinical outcomes for patients with or without a PTPN11 mutation. The survival of patients with a PTPN11 mutation was significantly inferior to survival of patients without (25 versus 64\%; $p=0.0029$ ) as shown in Figure 1. Of the patients without PTPN11 mutation, survival

Table 3. Correlation between mutational status and clinical characteristics in JMML

\begin{tabular}{|c|c|c|c|c|c|}
\hline & \multicolumn{5}{|c|}{ Mutational group } \\
\hline & $\begin{array}{c}\text { PTPN11, } \\
n=32(45 \%)\end{array}$ & $\begin{array}{c}\text { NRAS/KRAS, } \\
n=13(18 \%)\end{array}$ & $p^{*}$ & $\begin{array}{c}\text { No aberrations, } \\
n=23(32 \%)\end{array}$ & $p^{*}$ \\
\hline Median age at diagnosis, mo & 35 & 10 & $<0.0001$ & 10 & 0.0037 \\
\hline Older than 24 mo, no. & 24 & 1 & $<0.0001$ & 8 & 0.0067 \\
\hline 24 mo or younger, no. & 8 & 12 & & 15 & \\
\hline \multicolumn{6}{|l|}{ Gender, male/female } \\
\hline Male, no. & 22 & 8 & NS & 12 & NS \\
\hline Female, no. & 10 & 5 & & 11 & \\
\hline Median HbF level, \% & 25.6 & 8.6 & 0.0026 & 9.8 & 0.0014 \\
\hline More than $10 \%$, no. & 29 & 5 & 0.0008 & 11 & 0.0023 \\
\hline $10 \%$ or less, no. & 3 & 8 & & 12 & \\
\hline Median WBC count, $\times 10^{9} / \mathrm{L}$ & 27.7 & 29.4 & NS & 36.0 & NS \\
\hline Median platelets count, $\times 10^{9} / \mathrm{L}$ & 38.5 & 55.0 & NS & 45.0 & NS \\
\hline Less than $40 \times 10^{9} / \mathrm{L}$, no. & 17 & 5 & NS & 10 & NS \\
\hline $40 \times 10^{9} / \mathrm{L}$ or more, no. & 15 & 8 & & 13 & \\
\hline \multicolumn{6}{|l|}{ Cytogenetics } \\
\hline Abnormal karyotype, no. & 11 & 2 & NS & 2 & NS \\
\hline Monosomy 7, no. & 4 & 2 & NS & 2 & NS \\
\hline Other abnormalities, no. & 7 & 0 & & 0 & \\
\hline Normal karyotype, no. & 21 & 11 & & 21 & \\
\hline No. of patients received HSCT & 28 & 6 & 0.0107 & 11 & 0.0023 \\
\hline
\end{tabular}

* These were compared with those of PTPN11 group.

WBC, white blood cell; NS, not significant. 


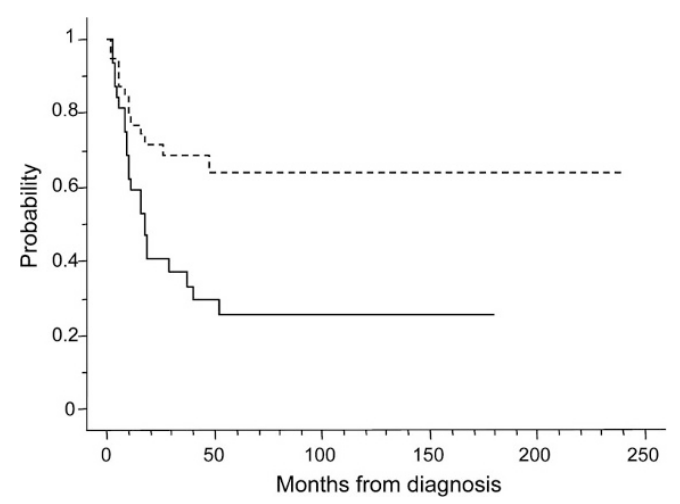

Figure 1. Kaplan-Meier estimate of overall survival in all patients according to PTPN11 mutation status. PTPN11-mutation group $(n=32)$ : solid lines PTPN11 wild-type group $(n=39)$ : broken line. The survival of PTPN11mutation group was significantly inferior to survival of PTPN11 wild-type group: $25 \%$ (95\% CI: 17-33) vs 64\% (95\% CI: 56-72); $p=0.0029$.

Table 4. Probability of 5-y overall survival (OS) in 71 patients with JMML

\begin{tabular}{|c|c|c|c|c|}
\hline Variable & $\begin{array}{l}\text { No. of } \\
\text { patients }\end{array}$ & $\begin{array}{c}\text { Probability } \\
(\%)\end{array}$ & $95 \% \mathrm{CI}$ & $p$ \\
\hline \multicolumn{5}{|l|}{ Mutational status } \\
\hline PTPN11 mutation & 32 & 25 & $17-33$ & 0.0029 \\
\hline PTPN11 wild type & 39 & 64 & $56-72$ & \\
\hline$R A S$ mutation & 13 & 61 & $45-78$ & \\
\hline No aberration & 23 & 65 & $55-75$ & \\
\hline \multicolumn{5}{|l|}{ Age at diagnosis } \\
\hline Older than $24 \mathrm{mo}$ & 35 & 33 & $25-42$ & 0.0030 \\
\hline 24 mo or younger & 36 & 58 & $48-67$ & \\
\hline \multicolumn{5}{|l|}{ Cytogenetics } \\
\hline Abnormal karyotype & 16 & 22 & $11-34$ & 0.0125 \\
\hline Normal karyotype & 55 & 53 & $46-61$ & \\
\hline \multicolumn{5}{|l|}{ Platelets count } \\
\hline Less than $40 \times 10^{9} / \mathrm{L}$ & 34 & 43 & $34-52$ & NS \\
\hline $40 \times 10^{9} / \mathrm{L}$ or more & 37 & 49 & $40-58$ & \\
\hline \multicolumn{5}{|l|}{$\mathrm{HbF}$ level } \\
\hline More than $10 \%$ & 47 & 41 & $33-49$ & NS \\
\hline $10 \%$ or less & 24 & 57 & $45-69$ & \\
\hline \multicolumn{5}{|l|}{ Gender } \\
\hline Male & 43 & 43 & $35-51$ & NS \\
\hline Female & 28 & 49 & $38-60$ & \\
\hline
\end{tabular}

NS, not significant.

values for the $R A S$ mutation group and the no aberration group were 61 and $65 \%$, respectively. The three patients with NF1 all received HSCT. One patient died because of transplantation-related toxicity and the others survived without the disease. The prognostic significance of the initial clinical and laboratory parameters, together with mutational status, is shown in Table 4. In the univariate analysis, age greater than 24 mo $(p=0.0030)$ and presence of cytogenetic abnormality $(p=0.0125)$ were associated with poor prognosis, as was the presence of PTPN11 mutation. Of particular interest cytogenetically is the fact that patients with monosomy 7 had a comparable outcome to that of children with a normal karyotype. However, all seven patients with an abnormal karyotype other than monosomy 7 died, and all had a PTPN11 mutation. Multivariate analysis showed that none of the variables influenced survival (Table 6).
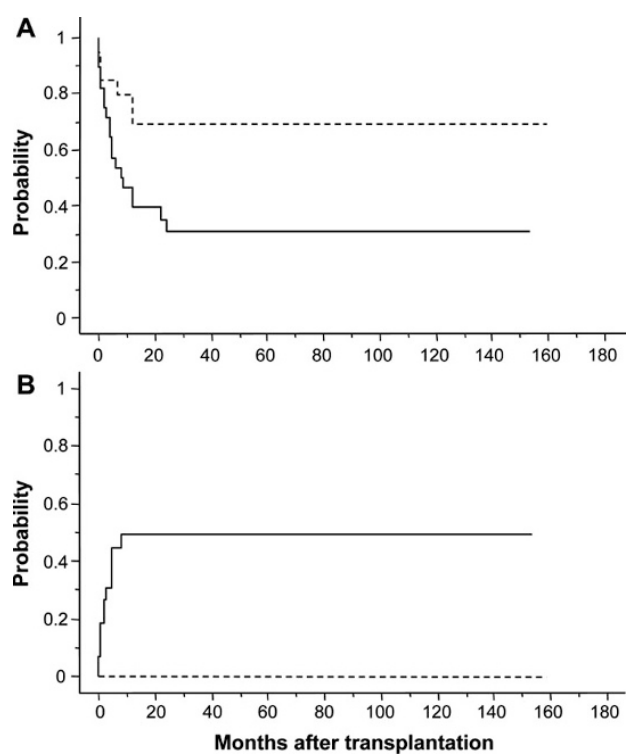

Figure 2. Kaplan-Meier estimate of overall survival and probability of relapse after HSCT in 48 patients according to PTPN11 mutation status. PTPN11-mutation group $(n=28)$ : solid lines. PTPN11 wild-type group $(n=$ 20): broken lines. (A) Overall survival. PTPN11-mutation group had significantly lower survival than PTPN11 wild-type group: 30\% (95\% CI: 21-39) vs 69\% (95\% CI: 59-80); $p=0.018$. (B) Relapse incidence. Whereas no relapse was observed in $P T P N 11$ wild-type group, the relapse incidence of PTPN11-mutation group was 49\% (95\% CI: $39-60) ; p=0.001$.

We then analyzed the prognostic value of PTPN11 mutations in the 48 of 71 patients who received HSCT. PTPNI1 mutations were found in 28 of 48 (58\%) patients, and of the 48 patients, 25 patients died after HSCT. As shown in Figure 2A, patients with a PTPN11 mutation had significantly lower survival than patients without also in this cohort. (30 versus $69 \% ; p=0.018)$. We found that the presence of a PTPNII mutation was the most significantly associated factor with OS after HSCT, and followed by age greater than $24 \mathrm{mo}$ and presence of cytogenetic abnormality (Fig. $3 A$ and Table 5). No variables significantly associated with inferior survival after HSCT in a multivariate model (Table 6). In addition, we compared the probability of relapse after HSCT between patients with and without PTPN11 mutations and found that the patients with a PTPN11 mutation had significantly higher risk for relapse $(p=0.001)$ (Fig. $2 B)$. No other variables including older age and cytogenetic abnormality arose statistically significant difference with the probability of relapse after HSCT (Fig. 3B and Table 5). Twelve patients died of relapse after transplantation and 13 died of transplantationrelated toxicity. Notably, all 12 patients who died after relapse had a PTPN11 mutation.

All four patients with a PTPN11 mutation who did not receive HSCT died (at 3, 4, 19, and 29 mo after diagnosis), whereas 12 of 19 patients without a PTPN11 mutation who did not receive HSCT remain alive, with a median follow-up of 80 mo (range, 21-240 mo) from diagnosis.

\section{DISCUSSION}

Since the discovery of PTPN11 mutations in JMML (9), biomedical and molecular research on this disease has pro- 
gressed rapidly, and data on molecular aberrations are now of great importance in the diagnosis of JMML. In the current study, we confirmed that PTPNII mutations are the most frequent molecular aberrations $(45 \%)$ in Japanese children with JMML. If a PTPN11 mutation is present, it is important to rule out the possibility of NS, especially in infants, because the JMML-like disorder in these patients may spontaneously disappear without therapy, so it is considered distinct from common JMML (31). All mutations detected in our cohort were located in exons 3 and 13 of the PTPN11 gene, which
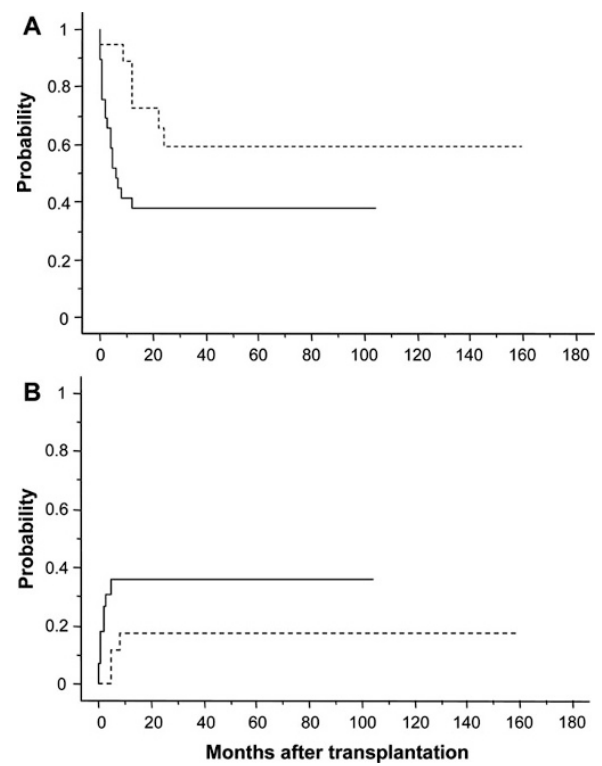

Figure 3. Kaplan-Meier estimate of overall survival and probability of relapse after HSCT in 48 patients according to age at diagnosis. Age $>24 \mathrm{mo}$ $(n=29)$ : solid lines. Age $\leqq 24$ mo $(n=19)$ : broken lines. $(A)$ Overall survival. Age $\leqq 24$ mo: $59 \%$ (95\% CI: 47-71) vs Age $>24$ mo: $38 \%$ (95\% CI: 29-47); $p=0.033$. (B) Relapse incidence. Age $\leqq 24$ mo: $19 \%$ (95\% CI: 9-29) vs Age $>24$ mo: $35 \%$ (95\% CI: $26-45) ; p=$ NS. accords with previous findings that mutations associated with JMML exist only in these two exons $(9,16)$. In contrast, mutations in NS are located in a much broader range of locations, in exons 2, 3, 4, 7, 8, and 13 (29). Kratz et al. (32) clearly demonstrated that a different spectrum of PTPN11 mutations between JMML and JMML-like disorder with NS. According to Kratz et al., all mutations in the present study were those associated with JMML, not a JMML-like disorder. These findings suggest that our study population included only patients with common JMML and that the observed mutations are somatic changes.

The prevalence of PTPN11 mutations in our cohort was slightly higher than that reported previously (9-11), and the prevalence of $R A S$ mutations was comparable with that found in previous studies $(2,6-8)$. In other studies, the proportion of patients with clinically diagnosed NF1 has been found to be 9 and $14 \%(1,33)$, but in our cohort, the proportion was smaller, only 3 of 71 (4\%) patients. A similar NF1 prevalence (4 of 83 patients; 5\%) was observed in an ongoing prospective study conducted by the MDS Committee of the Japanese Society of Pediatric Hematology, so NF1 might be less prevalent in the Japanese population. Another possibility is that NF1 was under diagnosed because of the paucity of signs and symp-

Table 6. Multivariate analysis of survival for all 71 patients and 48 patients who received HSCT

\begin{tabular}{cccc}
\hline & Relative risk & $95 \%$ CI & $p$ \\
\hline All patients $(n=71)$ & & & \\
$P T P N 11$ mutation & 1.854 & $0.852-5.139$ & NS \\
Older than 24 mo & 2.011 & $0.925-4.790$ & NS \\
Abnormal karyotype & 1.793 & $0.800-5.401$ & NS \\
Patients received HSCT $(n=48)$ & & \\
PTPN11 mutation & 2.226 & $0.852-5.814$ & NS \\
Older than 24 mo & 1.707 & $0.742-3.925$ & NS \\
Abnormal karyotype & 1.863 & $0.764-4.542$ & NS \\
\hline
\end{tabular}

NS, not significant.

Table 5. Univariate analysis of 5-y overall survival $(O S)$ and relapse incidence (RI) after HSCT in 48 patients with JMML

\begin{tabular}{|c|c|c|c|c|c|c|c|}
\hline \multirow[b]{2}{*}{ Variable } & \multirow[b]{2}{*}{ No. of patients } & \multicolumn{3}{|c|}{ OS } & \multicolumn{3}{|c|}{ RI } \\
\hline & & Probability $(\%)$ & $95 \% \mathrm{CI}$ & $p$ & Probability $(\%)$ & $95 \% \mathrm{CI}$ & $p$ \\
\hline \multicolumn{8}{|l|}{ Mutational status } \\
\hline PTPN11 mutation & 28 & 30 & $21-39$ & 0.0181 & 49 & $39-60$ & 0.0012 \\
\hline PTPN11 wild type & 20 & 69 & $59-80$ & & 0 & $0-0$ & \\
\hline$R A S$ mutation & 6 & 63 & $41-83$ & & 0 & $0-0$ & \\
\hline No aberration & 11 & 72 & $59-86$ & & 0 & $0-0$ & \\
\hline \multicolumn{8}{|l|}{ Age at diagnosis } \\
\hline Older than 24 mo & 29 & 38 & $29-47$ & 0.0331 & 35 & $26-45$ & NS \\
\hline 24 mo or younger & 19 & 59 & $47-71$ & & 19 & $9-29$ & \\
\hline \multicolumn{8}{|l|}{ Cytogenetics } \\
\hline Abnormal karyotype & 14 & 17 & $4-30$ & 0.0474 & 48 & $32-64$ & NS \\
\hline Normal karyotype & 34 & 56 & $47-64$ & & 23 & $15-30$ & \\
\hline \multicolumn{8}{|l|}{ Platelets count } \\
\hline Less than $40 \times 10^{9} / \mathrm{L}$ & 27 & 50 & $41-60$ & NS & 22 & $13-30$ & NS \\
\hline $40 \times 10^{9} / \mathrm{L}$ or more & 21 & 40 & $29-51$ & & 41 & $29-53$ & \\
\hline \multicolumn{8}{|l|}{$\mathrm{HbF}$ level } \\
\hline More than $10 \%$ & 37 & 45 & $37-54$ & NS & 33 & $24-42$ & NS \\
\hline $10 \%$ or less & 11 & 56 & $40-72$ & & 26 & $10-42$ & \\
\hline \multicolumn{8}{|l|}{ Gender } \\
\hline Male & 29 & 40 & $30-49$ & NS & 33 & $23-42$ & NS \\
\hline Female & 19 & 56 & $44-68$ & & 24 & $13-34$ & \\
\hline
\end{tabular}

NS, not significant. 
toms in young children. Niemeyer et al. (1) found that patients with NF1 were more likely to have higher platelet counts and normal karyotypes. In our patients with NF1, no clinical parameters except for age seemed to differ from the other groups, although the number of patients was too small to draw any conclusions. The outcome of patients with NF1 remains unclear; therefore, further accumulations of prognostic data in this condition are needed.

Our analysis showed a striking correlation between mutational status and clinical and laboratory findings of known prognostic factors. Compared with the RAS mutation group and the no aberration group, age and HbF level at diagnosis were significantly higher in the PTPN11 mutation group. Given that in previous reports older age at diagnosis and elevated $\mathrm{HbF}$ level have been repeatedly described as risk factors for survival (1,19-21,23-26), these results suggest that JMML with PTPN11 mutation is a distinct subgroup and that the outcome for patients with this condition might be poorer. In this study, both PTPN11 mutation and age were the strongest predictors of the probability of survival in univariate analyses. The poor survival of the PTPN11 mutation group was also observed when only the patients who had been treated with HSCT were included in the analysis. Because multivariate analysis did not discriminate between age and PTPN11 mutation, it remains unclear whether mutation in PTPN11 is an independent predictor for poor survival. However, this could possibly be ascribed to the strong relationship between the PTPN11 mutation group and older age. Poor outcome in patients with a PTPN11 mutation may be due to the presence of several unfavorable factors, suggesting that previously recognized prognostic factors might reflect the genetic status.

Presently, HSCT is the only curative treatment for JMML; however, disease recurrence remains the major cause of treatment failure. Notably, mutation in PTPN11 was the only risk factor for relapse after HSCT in our study. Previously published studies have found that older age, elevated HbF level, and abnormal karyotype are patient-specific risk factors for relapse after HSCT $(20,21)$. The finding that our patients with a PTPN11 mutation had an association with all these factors and our results on risk factors for relapse also support the idea that the genetic status may be an explanation of previous prognostic factors.

In our study, all 12 patients who relapsed after HSCT had a PTPN11 mutation, suggesting that patients with PTPN11 mutation may experience an aggressive clinical course. In addition, patients with PTPN11 mutation were more likely to receive $\mathrm{HSCT}$, also suggesting that there was a bias attributable to the aggressive clinical course in these patients. Indeed, all patients in the $P T P N 11$ mutation group who did not receive HSCT died, whereas five of seven patients in the RAS mutation group and seven of 12 patients in the no aberration group were alive without HSCT. Moreover, all patients with an abnormal karyotype other than monosomy 7 had a PTPN11 mutation, and all died, suggesting that clones with a PTPN11 mutation might be more likely to acquire additional chromosomal alterations.
To the best of our knowledge, this is the first report to investigate the prognostic relevance of the GM-CSF signaling pathway-related genes in patients with JMML and demonstrate the correlation between mutational status and recognized prognostic factors. The finding that mutations in PTPN11 or RAS and a clinical diagnosis of NF1 were mutually exclusive is consistent with the idea that these molecules act in the same pathway. Nonetheless, the clinical features were quite different in these groups. This difference might be caused by distinct gain-of-function effects of each gene on the GM-CSF pathway and unknown additional genetic alterations may cooperate with these mutations. Furthermore, considering the present and previous findings together, the previously recognized prognostic factors might reflect the genetic status of this pathway. Further biologic studies are necessary to clarify what kind of genetic alterations cooperate with altered GM-CSF pathway-related genes during the development of JMML.

In conclusion, JMML with mutation in PTPN11 seems to be a distinct subgroup with specific clinical characteristics and poor outcome. Consideration should be given to early HSCT therapy in this group of patients and better strategies to lower the risk of relapse in these patients are warranted.

Acknowledgments. The authors thank all of the patients, families, and referring physicians who contributed samples to the investigators.

\section{REFERENCES}

1. Niemeyer CM, Arico M, Basso G, Biondi A, Cantu Rajnoldi A, Creutzig U, Haas O, Harbott J, Hasle H, Kerndrup G, Locatelli F, Mann G, Stollmann-Gibbels B, van't Veer-Korthof ET, van Wering E, Zimmermann M 1997 Chronic myelomonocytic leukemia in childhood: a retrospective analysis of 110 cases. European Working Group on Myelodysplastic Syndromes in Childhood (EWOG-MDS). Blood 89:3534-3543

2. Lauchle JO, Braun BS, Loh ML, Shannon K 2006 Inherited predispositions and hyperactive Ras in myeloid leukemogenesis. Pediatr Blood Cancer 46:579-585

3. Emanuel PD, Bates LJ, Castleberry RP, Gualtieri RJ, Zuckerman KS 1991 Selective hypersensitivity to granulocyte-macrophage colony-stimulating factor by juvenile chronic myeloid leukemia hematopoietic progenitors. Blood 77:925-929

4. Emanuel PD 2004 Juvenile myelomonocytic leukemia. Curr Hematol Rep 3:203209

5. Side LE, Emanuel PD, Taylor B, Franklin J, Thompson P, Castleberry RP, Shannon KM 1998 Mutations of the NF1 gene in children with juvenile myelomonocytic leukemia without clinical evidence of neurofibromatosis, type 1. Blood 92:267-272

6. Flotho C, Valcamonica S, Mach-Pascual S, Schmahl G, Corral L, Ritterbach J, Hasle H, Arico M, Biondi A, Niemeyer CM 1999 RAS mutations and clonality analysis in children with juvenile myelomonocytic leukemia (JMML). Leukemia 13:32-37

7. Hirsch-Ginsberg C, LeMaistre AC, Kantarjian H, Talpaz M, Cork A, Freireich EJ, Trujillo JM, Lee MS, Stass SA 1990 RAS mutations are rare events in Philadelphia chromosome-negative/bcr gene rearrangement-negative chronic myelogenous leukemia, but are prevalent in chronic myelomonocytic leukemia. Blood 76:1214-1219

8. Kalra R, Paderanga DC, Olson K, Shannon KM 1994 Genetic analysis is consistent with the hypothesis that NF1 limits myeloid cell growth through p21ras. Blood 84:3435-3439

9. Tartaglia M, Niemeyer CM, Fragale A, Song X, Buechner J, Jung A, Hahlen K, Hasle H, Licht JD, Gelb BD 2003 Somatic mutations in PTPN11 in juvenile myelomonocytic leukemia, myelodysplastic syndromes and acute myeloid leukemia. Nat Genet 34:148-150

10. Neel BG, Gu H, Pao L 2003 The 'Shp'ing news: SH2 domain-containing tyrosine phosphatases in cell signaling. Trends Biochem Sci 28:284-293

11. Tartaglia M, Martinelli S, Cazzaniga G, Cordeddu V, Iavarone I, Spinelli M, Palmi C, Carta C, Pession A, Arico M, Masera G, Basso G, Sorcini M, Gelb BD, Biondi A 2004 Genetic evidence for lineage-related and differentiation stage-related contribution of somatic PTPN11 mutations to leukemogenesis in childhood acute leukemia. Blood 104:307-313

12. Flotho C, Steinemann D, Mullighan CG, Neale G, Mayer K, Kratz CP, Schlegelberger B, Downing JR, Niemeyer CM 2007 Genome-wide single-nucleotide polymorphism analysis in juvenile myelomonocytic leukemia identifies uniparental disomy surrounding the NF1 locus in cases associated with neurofibromatosis but not in cases with mutant RAS or PTPN11. Oncogene 26:5816-5821 
13. Largaespada DA, Brannan CI, Jenkins NA, Copeland NG 1996 Nf1 deficiency causes Ras-mediated granulocyte/macrophage colony stimulating factor hypersensitivity and chronic myeloid leukaemia. Nat Genet 12:137-143

14. Lanfrancone L, Pelicci G, Brizzi MF, Aronica MG, Casciari C, Giuli S, Pegoraro L, Pawson T, Pelicci PG, Arouica MG 1995 Overexpression of Shc proteins potentiates the proliferative response to the granulocyte-macrophage colony-stimulating factor and recruitment of Grb2/SoS and Grb2/p140 complexes to the beta receptor subunit. Oncogene 10:907-917

15. Tartaglia M, Mehler EL, Goldberg R, Zampino G, Brunner HG, Kremer H, van der Burgt I, Crosby AH, Ion A, Jeffery S, Kalidas K, Patton MA, Kucherlapati RS, Gelb BD 2001 Mutations in PTPN11, encoding the protein tyrosine phosphatase SHP-2, cause Noonan syndrome. Nat Genet 29:465-468

16. Loh ML, Vattikuti S, Schubbert S, Reynolds MG, Carlson E, Lieuw KH, Cheng JW, Lee CM, Stokoe D, Bonifas JM, Curtiss NP, Gotlib J, Meshinchi S, Le Beau MM, Emanuel PD, Shannon KM 2004 Mutations in PTPN11 implicate the SHP-2 phosphatase in leukemogenesis. Blood 103:2325-2331

17. Loh ML, Reynolds MG, Vattikuti S, Gerbing RB, Alonzo TA, Carlson E, Cheng JW, Lee CM, Lange BJ, Meshinchi S 2004 PTPN11 mutations in pediatric patients with acute myeloid leukemia: results from the Children's Cancer Group. Leukemia 18:1831-1834

18. Luna-Fineman S, Shannon KM, Atwater SK, Davis J, Masterson M, Ortega J, Sanders J, Steinherz P, Weinberg V, Lange BJ 1999 Myelodysplastic and myeloproliferative disorders of childhood: a study of 167 patients. Blood 93:459-466

19. Passmore SJ, Hann IM, Stiller CA, Ramani P, Swansbury GJ, Gibbons B, Reeves BR, Chessells JM 1995 Pediatric myelodysplasia: a study of 68 children and a new prognostic scoring system. Blood 85:1742-1750

20. Manabe A, Okamura J, Yumura-Yagi K, Akiyama Y, Sako M, Uchiyama H, Kojima S, Koike K, Saito T, Nakahata T 2002 Allogeneic hematopoietic stem cell transplantation for 27 children with juvenile myelomonocytic leukemia diagnosed based on the criteria of the International JMML Working Group. Leukemia 16:645-649

21. Locatelli F, Nollke P, Zecca M, Korthof E, Lanino E, Peters C, Pession A, Kabisch H, Uderzo C, Bonfim CS, Bader P, Dilloo D, Stary J, Fischer A, Revesz T, Fuhrer M, Hasle H, Trebo M, van den Heuvel-Eibrink MM, Fenu S, Strahm B, Giorgiani G, Bonora MR, Duffner U, Niemeyer CM 2005 Hematopoietic stem cell transplantation (HSCT) in children with juvenile myelomonocytic leukemia (JMML): results of the EWOG-MDS/EBMT trial. Blood 105:410-419

22. Matsuda K, Shimada A, Yoshida N, Ogawa A, Watanabe A, Yajima S, Iizuka S, Koike K, Yanai F, Kawasaki K, Yanagimachi M, Kikuchi A, Ohtsuka Y, Hidaka E, Yamauchi K, Tanaka M, Yanagisawa R, Nakazawa Y, Shiohara M, Manabe A, Kojima S 2007 Spontaneous improvement of hematologic abnormalities in patients having juvenile myelomonocytic leukemia with specific RAS mutations. Blood 109:5477-5480

23. Castro-Malaspina H, Schaison G, Passe S, Pasquier A, Berger R, Bayle-Weisgerber C, Miller D, Seligmann M, Bernard J 1984 Subacute and chronic myelomonocytic leukemia in children (juvenile CML). Clinical and hematologic observations, and identification of prognostic factors. Cancer 54:675-686

24. Hasle H, Baumann I, Bergstrasser E, Fenu S, Fischer A, Kardos G, Kerndrup G, Locatelli F, Rogge T, Schultz KR, Stary J, Trebo M, van den Heuvel-Eibrink MM, Harbott J, Nollke P, Niemeyer CM 2004 The International Prognostic Scoring System (IPSS) for childhood myelodysplastic syndrome (MDS) and juvenile myelomonocytic leukemia (JMML). Leukemia 18:2008-2014

25. Arico M, Bossi G, Schiro R, Galimberti M, Longoni D, Macchia P, Miniero R, Natale D, Pession A, Pillon M 1993 Juvenile chronic myelogenous leukemia: report of the Italian Registry. Associazione Italiana di Ematologia Oncologia Pediatrica (AIEOP). Haematologica 78:264-269

26. Owen G, Lewis IJ, Morgan M, Robinson A, Stevens RF 1992 Prognostic factors in juvenile chronic granulocytic leukaemia. Br J Cancer Suppl 18:S68-S71

27. Niemeyer CM, Fenu S, Hasle H, Mann G, Stary J, Wering E 1998 Differentiating juvenile myelomonocytic leukemia from infectious disease. Blood 91:365-367

28. Yamamoto T, Isomura M, Xu Y, Liang J, Yagasaki H, Kamachi Y, Kudo K, Kiyoi H, Naoe T, Kojma S 2006 PTPN11, RAS and FLT3 mutations in childhood acute lymphoblastic leukemia. Leuk Res 30:1085-1089

29. Tartaglia M, Kalidas K, Shaw A, Song X, Musat DL, van der Burgt I, Brunner HG, Bertola DR, Crosby A, Ion A, Kucherlapati RS, Jeffery S, Patton MA, Gelb BD 2002 PTPN11 mutations in Noonan syndrome: molecular spectrum, genotype-phenotype correlation, and phenotypic heterogeneity. Am J Hum Genet 70:1555-1563

30. Mitani K, Hangaishi A, Imamura N, Miyagawa K, Ogawa S, Kanda Y, Yazaki Y, Hirai H 1997 No concomitant occurrence of the N-ras and p53 gene mutations in myelodysplastic syndromes. Leukemia 11:863-865

31. Flotho C, Kratz CP, Niemeyer CM 2007 How a rare pediatric neoplasia can give important insights into biological concepts: a perspective on juvenile myelomonocytic leukemia. Haematologica 92:1441-1446

32. Kratz CP, Niemeyer CM, Castleberry RP, Cetin M, Bergstrasser E, Emanuel PD, Hasle H, Kardos G, Klein C, Kojima S, Stary J, Trebo M, Zecca M, Gelb BD, Tartaglia M, Loh ML 2005 The mutational spectrum of PTPN11 in juvenile myelomonocytic leukemia and Noonan syndrome/myeloproliferative disease. Blood 106:2183-2185

33. Stiller CA, Chessells JM, Fitchett M 1994 Neurofibromatosis and childhood leukaemia/lymphoma: a population-based UKCCSG study. Br J Cancer 70:969-972 